\title{
Computational fluid dynamics calculus and analysis for gas and water turbines
}

\author{
Valeriu Vilag, ${ }^{1, *}$, Ivanka Zheleva $^{2}$, Jenia Popescu $^{1}$ and Krasimir Tujarov ${ }^{2}$ \\ ${ }^{1}$ COMOTI Romanian Research and Development Institute for Gas Turbines, 061126 Bucharest, \\ Romania \\ 2"Anghel Kanchev" University of Ruse, 7017 Ruse, Bulgaria
}

\begin{abstract}
The paper presents the utilization of Computational Fluid Dynamics for calculating the flow through turbines. The first and most extended part of the paper is focused on gas turbines where the simulations are very precise and can be successfully used even for optimization of blade geometry. Flow details and results for an axial turbine are presented along with a proposal of optimization algorithm. The second part of the paper is dedicated to water turbines and there is presented the calculus realized for a kinetic water turbine. I this case, the flow around the turbine blades is presented and some data about the predicted performances along with many ways for improving the simulations. The conclusions of the paper are related to similarities and differences between the two types of simulations and to the many ways of using these simulations for practical applications.
\end{abstract}

\section{Introduction}

Energetic machines like gas and water turbine are in general use from many decades but their performances are still a research subject since new and improved methods for designing them can be applied. A very useful tool is in our days Computational Fluid Dynamics (CFD) thanks to the great advance in computing capabilities. Hence, any proposed design can be evaluated through numerical simulations and a decision between several ones is taken with way lower costs in comparison to when doing real experiments for all of them. The results are in very good correlation to the experimental results giving more and more confidence to the designers to use this evaluation tool even for optimization.

\section{Gas turbine simulations}

For gas turbines as a specific type of turbomachinery, there are many commercial CFD codes that give satisfactory results and pretty quick. A typical case study is presented below where an axial turbine having a stator blade row a rotor blade row is analyzed using ANSYS CFX.

\footnotetext{
* Corresponding author: valeriu.vilag@,comoti.ro
} 
The full geometry of the axial gas turbine stage is presented in Fig. 1 where there can be observed 30 stator blades and 61 rotor blades.

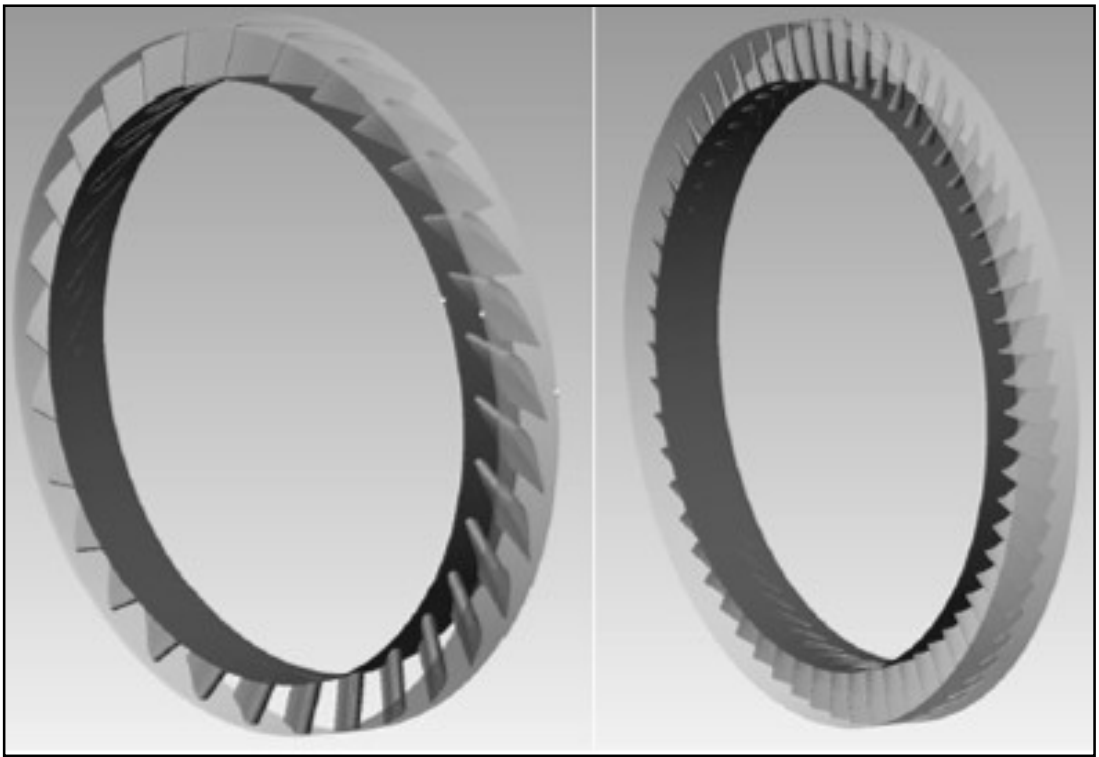

Fig. 1. Full axial gas turbine stage

Since the corresponding calculus domain for such a complex geometry would lead to very large computing time there is introduced a simplification which is very close to realty. So, it is considered that the blades belonging to the same row are identical and therefore the flows between them are also identical. When applying this hypothesis, also called periodicity of flow [1], for both stator and rotor we can reduce the calculus domain to only one stator blade and one rotor blade as shown in Fig. 2.

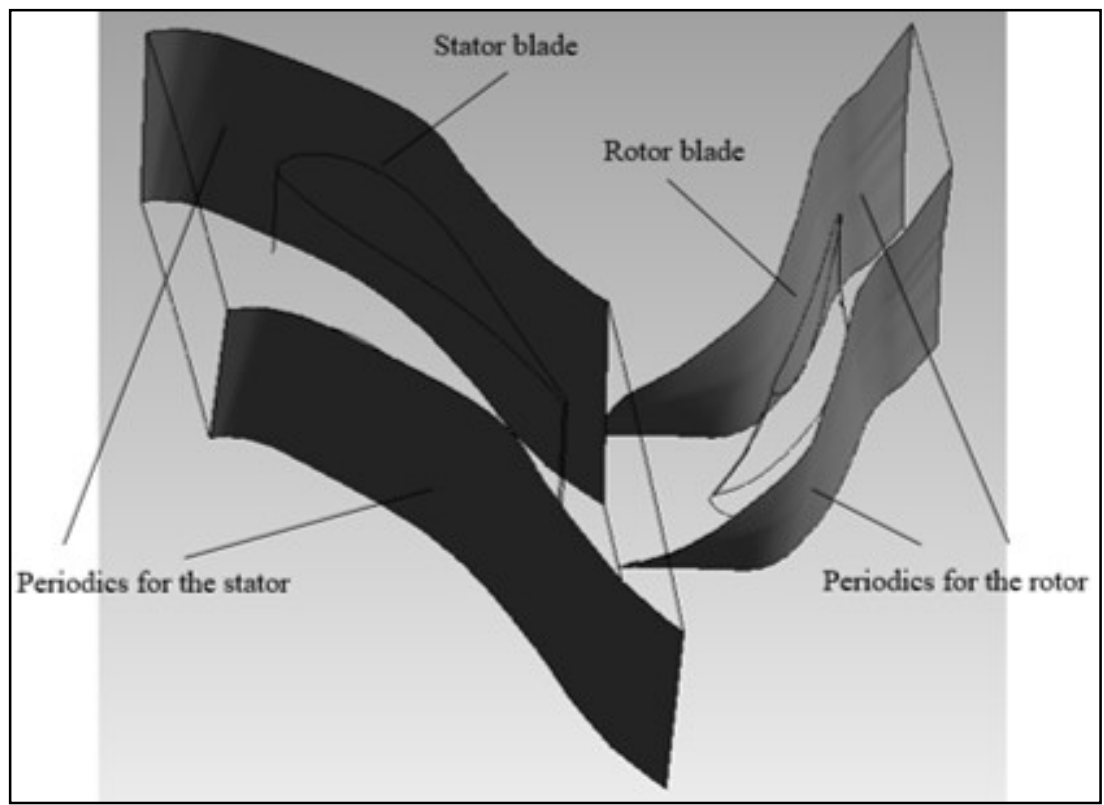

Fig. 2. Simplified domain using the so-called periodicity 
Once we have established the calculus domain, the next step consists in defining the grid or mesh. Many meshing tools exist also as commercial codes the main purpose being to obtain a discretization fine enough to capture all the geometrical features and coarse enough to reduce the computing time. We have to mention here that unlike for compressor simulations where mesh quality may affect the obtained results in a very complex way, for gas turbines the mesh quality is important for capturing the shape of the blade. The difference can be explained by the different flow characteristics as for the compressors the pressure must rises being a forced or unnatural process whereas for turbines the pressure naturally falls.

The case study continues with the boundary conditions where the flow is fully or partially known. In Table 1 there are presented the boundary conditions and their names as they appear in ANSYS CFX together with the imposed flow characteristics.

Table 1. Imposed flow characteristics on the boundaries

\begin{tabular}{|c|c|c|}
\hline No. & Boundary name & Flow characteristics \\
\hline 1 & Stator Inlet & Total temperature; Total Pressure \\
\hline 2 & Stator hub & \multirow{3}{*}{ No slip adiabatique wall, stationary } \\
\hline 3 & Stator shroud & \\
\hline 4 & Stator blade & \\
\hline 5 & $\begin{array}{c}\text { Periodics for the } \\
\text { stator }\end{array}$ & Periodic interface \\
\hline 6 & Stator Outlet & \multirow{2}{*}{ Fluid-to-fluid frozen rotor interface } \\
\hline 7 & Rotor Inlet & \\
\hline 8 & Rotor hub & \multirow{3}{*}{ No slip adiabatic wall rotating with $22000 \mathrm{rpm}$} \\
\hline 9 & Rotor shroud & \\
\hline 10 & Rotor blade & \\
\hline 11 & $\begin{array}{l}\text { Periodics for the } \\
\text { rotor }\end{array}$ & Periodic interface \\
\hline 12 & Rotor outlet & Mass flow rate (per one blade passage) \\
\hline
\end{tabular}

The fluid-to-fluid frozen rotor interface is a frame change model which is used to predict the transition from the stationary frame of the stator to the rotational frame of the rotor. It is one of the many possible choices to pass between frames and in combination with the periodic interfaces, for the stator and the rotor, gives satisfactory results even for multiple stage turbomachinery.

The solver requests also imposing the turbulence model, which in the present study is "k- $\varepsilon$ " and some other details of the computational model including different numerical methods coefficients. We don't discuss them in the current paper since the default settings from ANSYS CFX when entering "Turbo-mode" are very appropriate.

After the solver computes several iterations, usually around 500 for one turbine stage are enough, the results are generated and they can be post-processed to find the predicted performances [2]. A report can be automatically generated showing several useful 
parameters of the turbine stage, the most important ones being displayed in Table 2 for the presented case study.

Table 2. Computed results

\begin{tabular}{|c|c|c|}
\hline No. & Name & Value \\
\hline 1 & Rotor blade torque & $9.9884[\mathrm{Nm}]$ \\
\hline 2 & Total power & $1403[\mathrm{~kW}]$ \\
\hline 3 & $\begin{array}{c}\text { Total-to-total isentropic } \\
\text { efficiency }\end{array}$ & $87.654 \%$ \\
\hline 4 & Expansion ratio & 2.4581 \\
\hline
\end{tabular}

Apart from the computed values the user can display contours plots of flow variables like pressure and temperature, vectors, streamlines and other parameters showing the turbulence, energy loss etc. Pressure variation, Fig. 3, is used to evaluate the losses that are characteristics in turbomachinery like profile losses and secondary losses, while the temperatures. Fig. 4, are used when choosing the materials from which the turbine will be constructed.

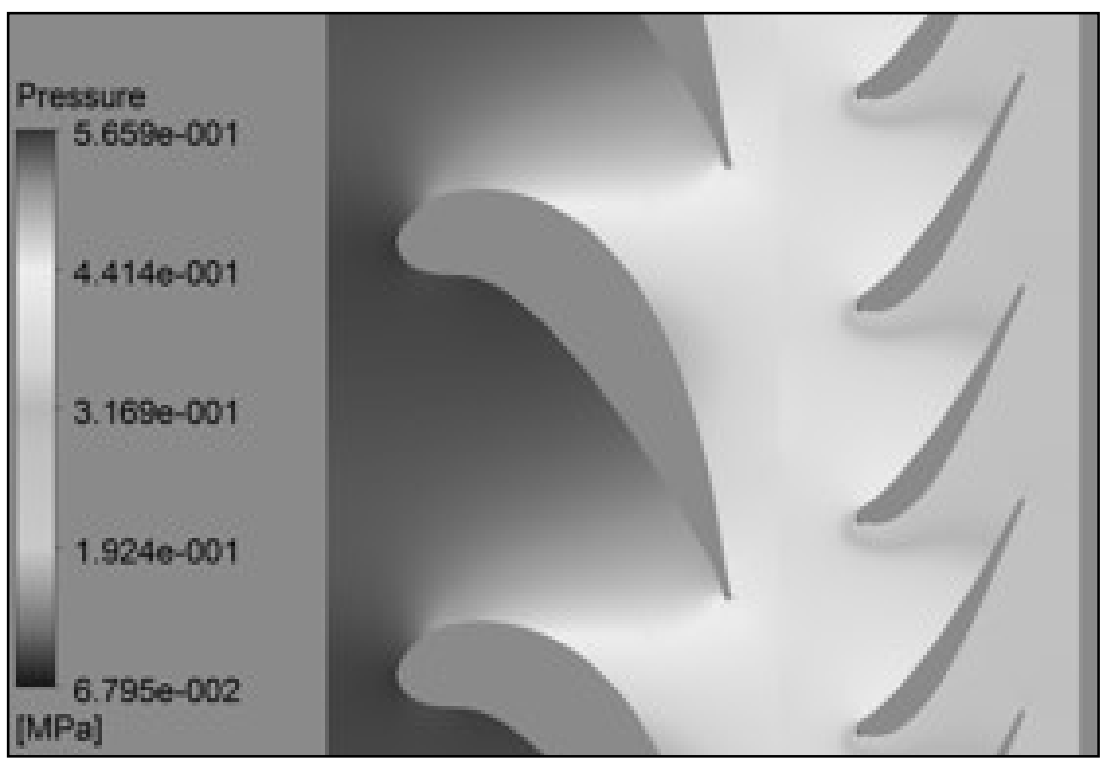

Fig. 3. Pressure variation at mid span 


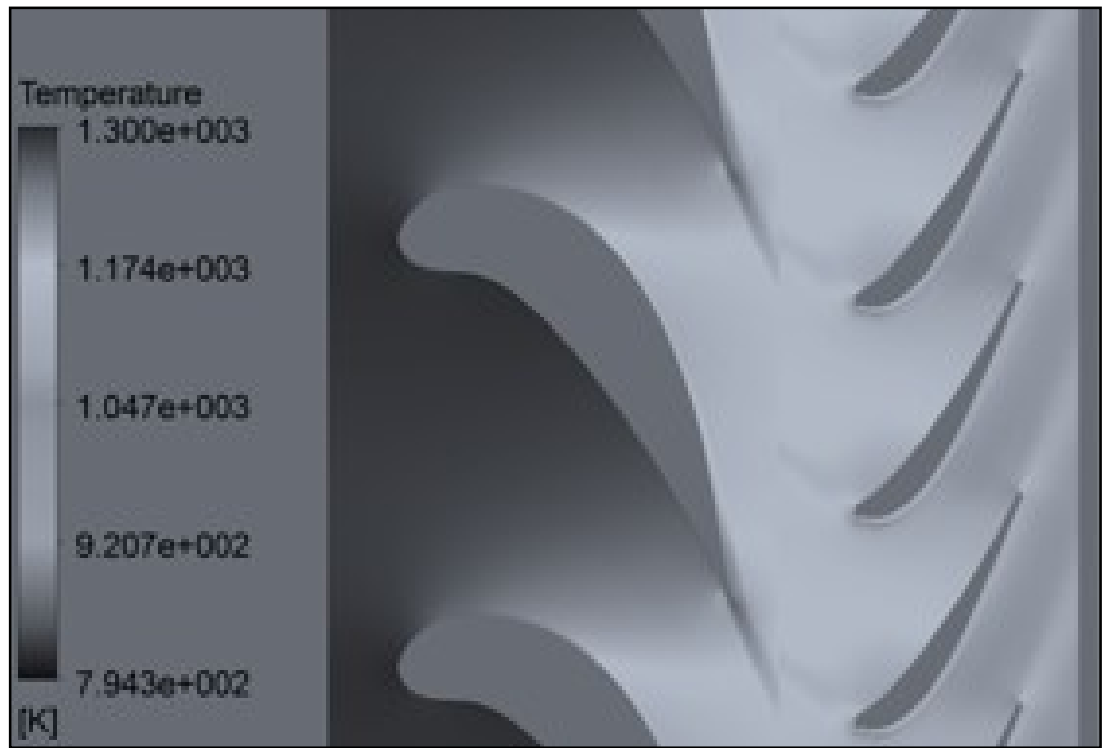

Fig. 4. Temperature variation at mid span

\section{Gas turbine optimization}

Optimization in the gas turbine field is seen as the quest for the optimum shape giving the desired performances and it is performed also using computers. Since it is always about shape, it all starts with defining the aerodynamic profile into the computer. There are many ways of defining a turbine row but the one presented in [4] is the most used since it contains all necessary and sufficient parameters for turbine design. In Fig. 5 we present these parameters, some being purely geometrical and some depicting the flow.

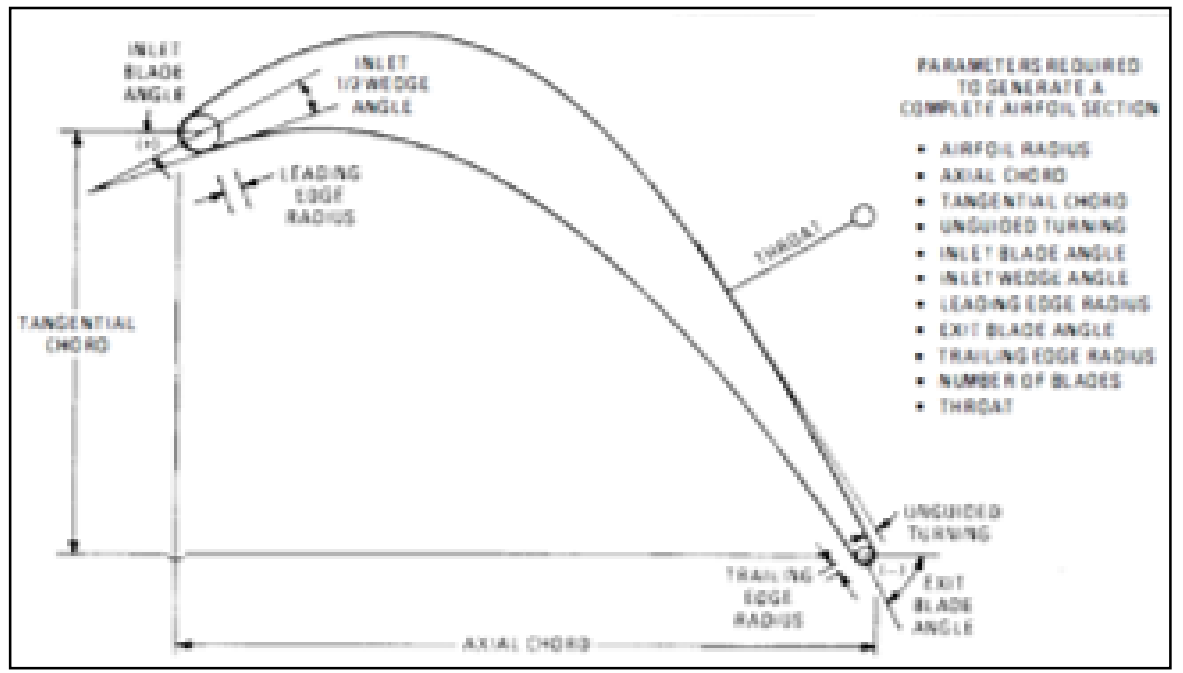

Fig. 5. Parameters defining a turbine row [3]. 
By imposing some limits for each of the parameters one can obtain a very wide design space consisting in many turbine geometries to be evaluated.

In Fig. 6 there is presented the shape evolution for a stator blade [4] when optimized using the algorithm presented in Fig. 7 where an initial population is created and then, via some operations inspired from the nature, new individuals are obtained.

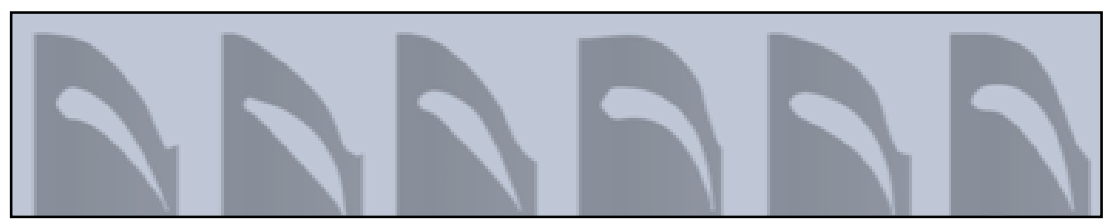

Fig. 6. Stator blade shape evolution

The presented algorithm is an evolutionary one meaning that it creates individuals at each step and then CFD evaluation tools can be used. Its convergence can be demonstrated but still, the finding of the optimum can consume a lot of computing effort.

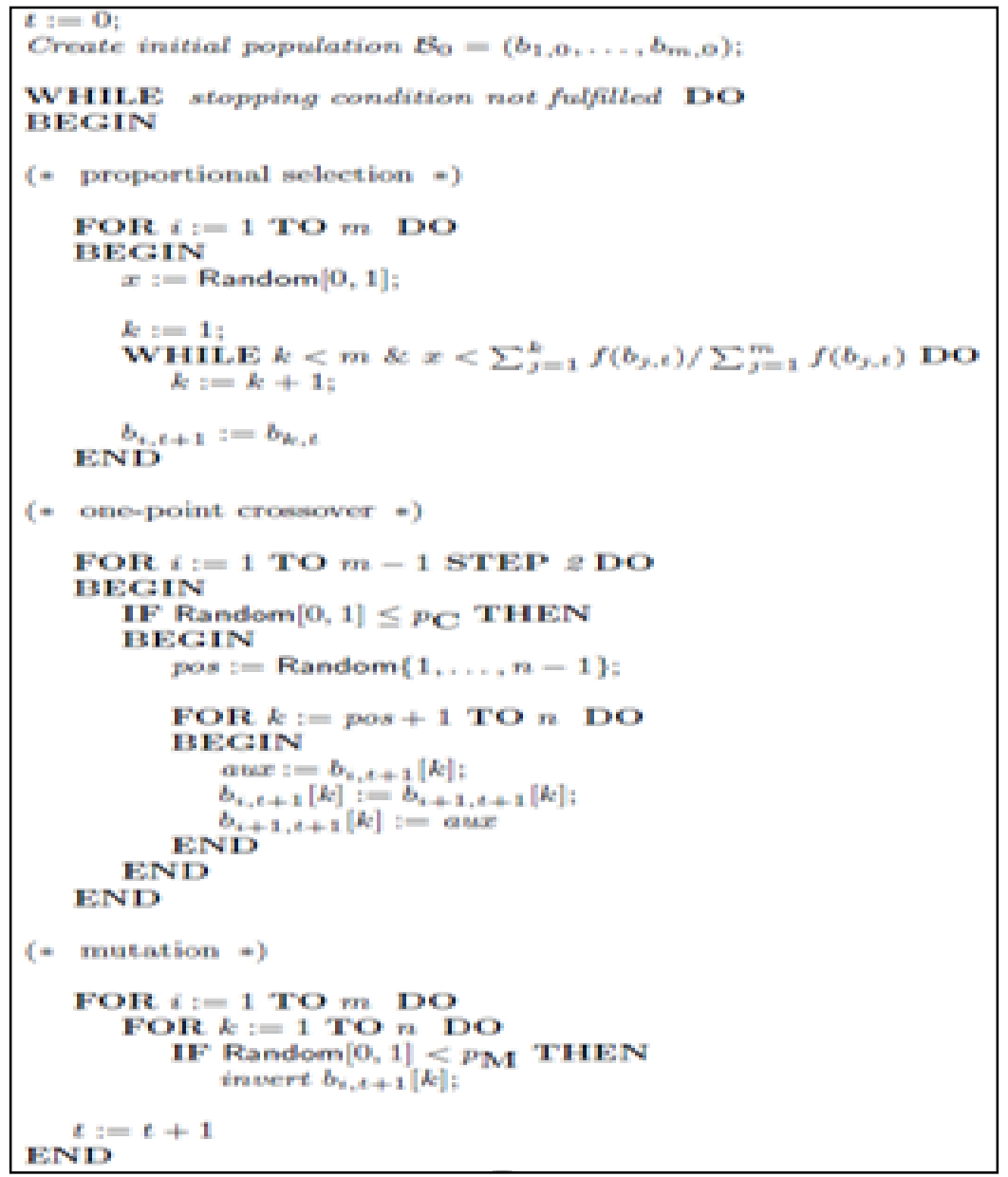

Fig. 7. Optimization algorithm [5] 


\section{Water turbine simulations}

This section is dedicated to kinetic water turbine simulations and it contains some insight view of the simulations performed in a Romanian-Bulgarian collaboration project. Unlike the gas turbine case, the kinetic water turbine is a specific type of turbomachinery which is very difficult to evaluate using numerical simulations and the obtained results are in many cases unsatisfactory [6]. Still, the steps are very similar to the ones for the gas turbine case and are briefly presented in Fig. 8 and 9.

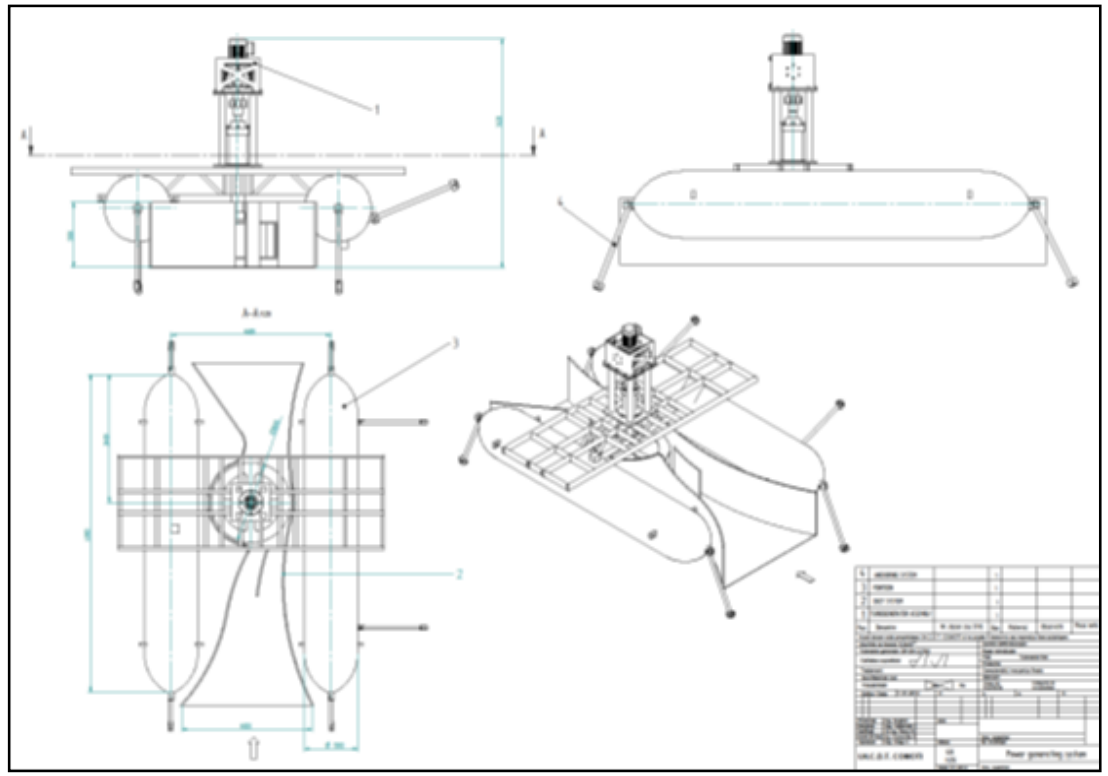

Fig. 8. General view of kinetic water turbine architecture

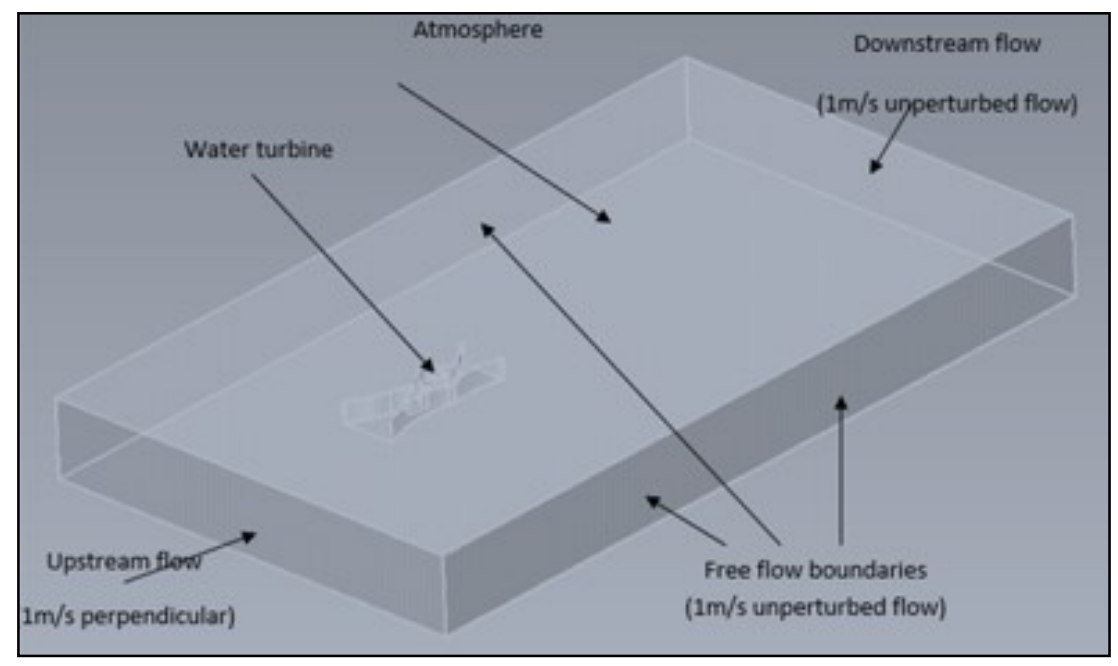

Fig. 9. Calculus domain and boundary conditions

Many simplifications where also employed, the most important being the one saying that the rotor is fully under water and it doesn't create waves. This hypothesis might not be valid for all the working regimes of the presented water turbine, but we consider that the numerical simulation still is able to give qualitative information. 
We present below some results in the form of contour plots at midspan of the kinetic turbine, Fig. 10 velocity variation.

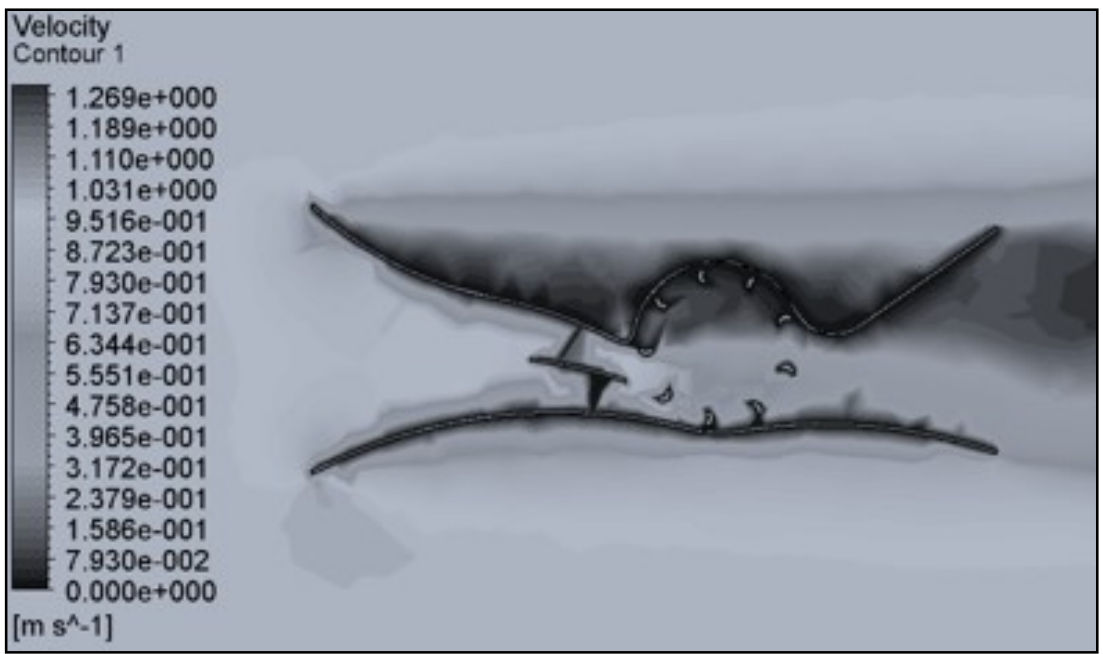

Fig. 10. Velocity magnitude at mid span

Velocity plots can be used to determine the efficiency of the kinetic water turbine highlighting also the areas where the flow has big gradients creating losses.

An indication about the waves can be seen by showing velocity vectors at the surface of the water, where the atmosphere begins, Fig. 11, but good results may be obtained only when modelling two phase flow water / air.

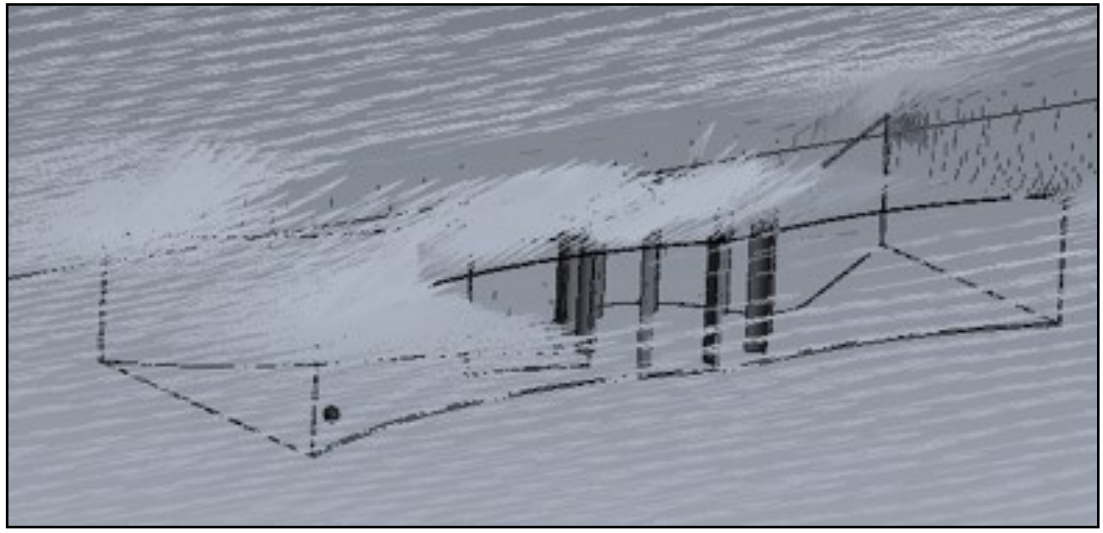

Fig. 11. Velocity vectors at the surface of the water.

Theoretical performance curves for kinetic water turbines are presented in Fig. 13, the points being obtained for tip speed ratios up to the value of 2 . 


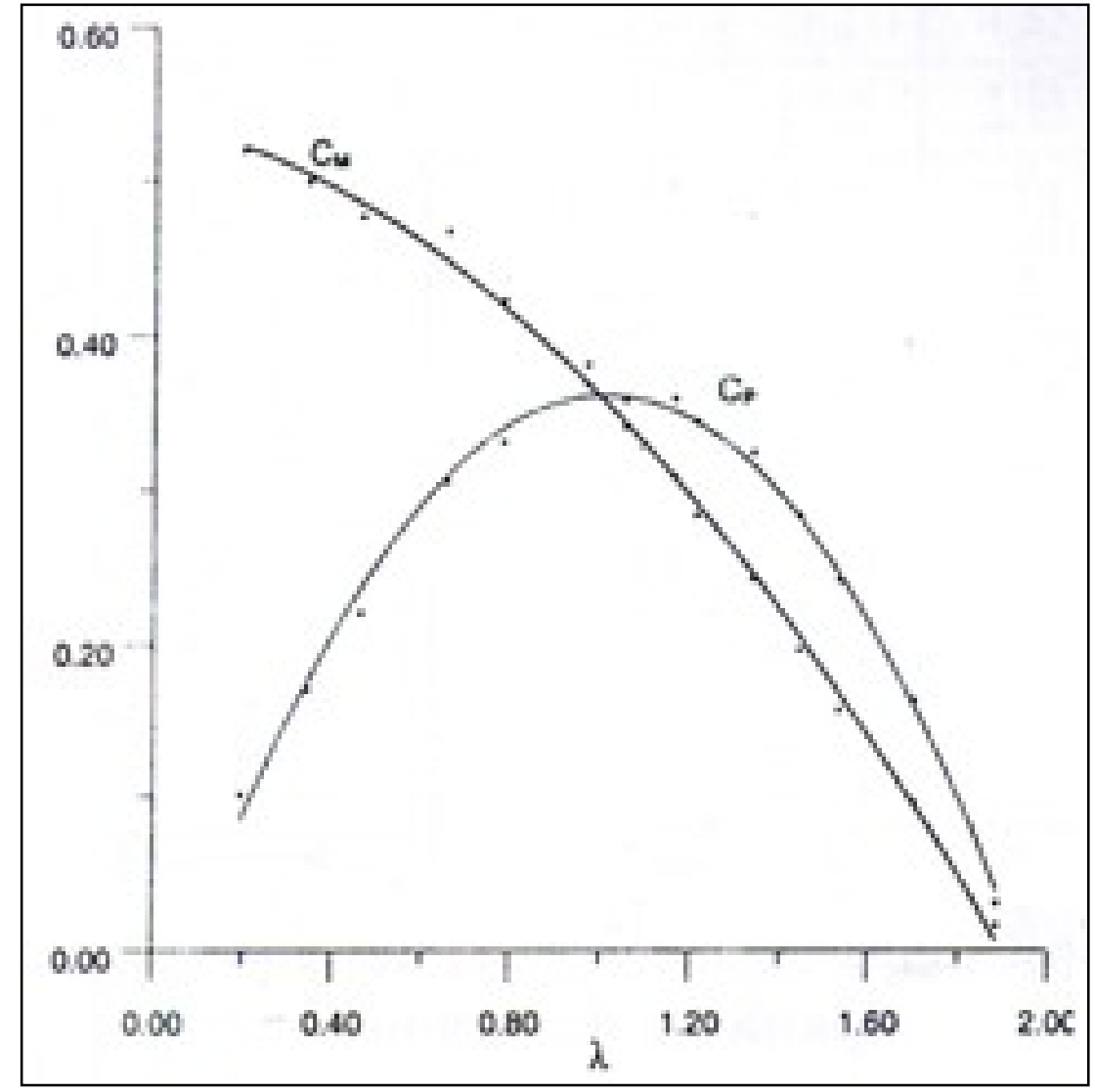

Fig. 12. Theoretical performance curves of kinetic water turbine.

\section{Conclusions}

When speaking about turbomachinery, CFD simulations are currently extensively used to conduct virtual experiments providing a good overview of the performances. For gas turbines, some specific hypothesis are applied in order to reduce the computational domain and hence to reduce the computational effort. Thus, they can be used even in optimization problems where a lot of evaluations must be performed in order to obtain optimum shapes. An evolutionary algorithm was presented and successfully used for stator blade optimization showing the wide design space a parametric model can offer.

A special type of turbomachinery is represented by turbines that extract the energy from natural flows like the wind turbines and kinetic water turbines are. For kinetic water turbines, although some results were presented, the complexity of the phenomena makes mandatory the improvement of the simulations in such way to be able to predict the water/air interface (waves) which is an important source of losses.

In conclusion, similar way of treating gas and kinetic water turbines is useful to some extent but, the later must be treated with much more precaution to obtain satisfactory results. 


\section{Acknowledgment}

The work presented herein was funded by the Romanian National Research Program Nucleu TURBO 2020 and the Romania - Bulgaria CBC Programme 2007-2013 (project "Joint study regarding an electro-generator system powered by water turbine for cross-border ecological electrical transport system - ElectroRiver", MIS ETC Code 128).

\section{References}

1. ANSYS CFX user guide;

2. Vilag V., Popescu J., Petcu R., Bogoi A., Silivestru V., Numerical study on an axial gas-turbine stage, Annals of DAAAM for 2008 \& Proceedings of the 19th International DAAAM Symposium, 22-25th October 2008, Trnava, Slovakia, ISSN 1726-9679, ISBN 978-3-901509-68-1, Katalinic, B. (Ed.), pp. 1397-1398, Published by DAAAM International Vienna, Vienna;

3. Pritchard, L. J., An Eleven Parameter Axial Turbine Airfoil Geometry Model, ASME 1985 International Gas Turbine Conference and Exhibit, Vol. 1: Aircraft Engine; Marine; Turbomachinery; Microturbines and Small Turbomachinery, Houston, Texas, USA, 1985;

4. Vilag V., Contributions regarding optimization of axial turbines using evolutionary algorithms and computational gasdynamics, Doctoral Thesis, Politehnica University of Bucharest, Faculty of Aerospace Engineering, July 2013;

5. Bodenhofer U., Genetic Algorithms: Theory and Applications, Lecture Notes Second Edition - WS 2001/2002, Institut für Algebra, Stochastik und wissensbasierte mathematische Systeme Johannes Kepler Universität, A-4040 Linz, Austria;

6. Dediu G., Vilag V., Popescu J., System instrumentation and data acquisition for TurboRiver-RB7, Annual Conference, “Angel Kanchev"University of Ruse, 2627.10.2012, Ruse, Bulgaria 